\title{
Positive Output Elementary Super Lift Luo Converter Using Pi Controller
}

\author{
S.Usha, C.Subramani, R.Muthulakshmi, R.Ramya, R.Kaveri, Harshit Singh
}

\begin{abstract}
An Electron device and circuits that converts an origin of direct current from one particular level of voltage to another is represent a boost converter. To achieve high step up voltage gain, it uses coupled inductor and the voltage lift technique. However, there is a reduced stress on the animated switch as it is attached and the energy deposited in the leakage conductor is reused, hence increasing its conversion efficiency. In this paper, a Proportional-Integral control has been designed for the positive output of the Elementary Super Lift LUO Converter using a bidirectional Capacitor, Super Lift LUO converter which uses the voltage lift capability to donate a less ripple, very high power density, higher efficiency, voltage gain and a less complicated structure. A comprehensive analysis and modeling was also implemented.
\end{abstract}

Keywords: LUO converter, switched capacitance, phase shifters, micro fabrication, inverter.

\section{INTRODUCTION}

DC to DC changes is an application that has been expanding rapidly and these are also generally used in industries as well. The positive output Luo converter is another series of DC to DC converter as it has high power density and efficiency. It is used in many industrial applications, Switched Mode Power Supply, etc. The block diagram for the PI Control has been given below.

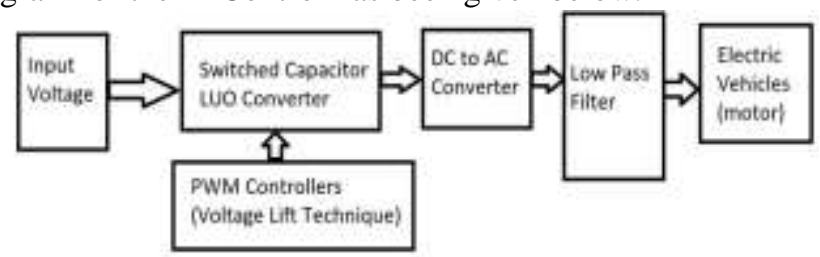

Figure 1. Proposed method block diagram

The proposed method considerably enlarge the Voltage Transfer Gain. However these circuits are complex in nature [1-2]. The static and dynamic behavior of the power converters becomes nonlinear due to the time variations and its switching nature. A good control over these converters ensures stability in arbitrary operation condition. The PI control method offers lot of advantages over the Proportional

Revised Version Manuscript Received on 10, September 2019.

S.Usha, SRM institute of science and technology, Kattankulathur, Chennai, Tamilnadu, India.

C. Subramani, SRM institute of science and technology, Kattankulathur, Chennai, Tamilnadu, India.

R.Muthulakshmi, SRM institute of science and technology, Kattankulathur, Chennai, Tamilnadu, India.

R.Ramya, SRM institute of science and technology, Kattankulathur, Chennai, Tamilnadu, India.

R.Kaveri, SRM institute of science and technology, Kattankulathur, Chennai, Tamilnadu, India.

Harshit Singh, SRM institute of science and technology, Kattankulathur, Chennai, Tamilnadu, India. derivative and integral control such as:-stability, robustness, good dynamic response and many more [3]. In this paper, a PI (Proportional- Integral) control has been designed for the positive output of the Elementary Super Lift LUO Converter [4-5].

\section{MATERIALS AND METHODS}

Switched capacitor- This is a circuit element preowned for processing of discrete time signal. When the switches are opened and closed, the charges move in and out of the capacitor [6]. The signals to the switches are usually controlled by non-overlapping signals. Since these filters based only on the ratios between the capacitances, they are more suitable for use within integrated circuits [7]. Switched capacitor resistor- This is the simplest circuit made of one capacitor and two switches. The combination of these three behaves like a resistor whose value depends on capacitors and frequency with the added benefit of adjusting the Value with a change in the frequency [8].

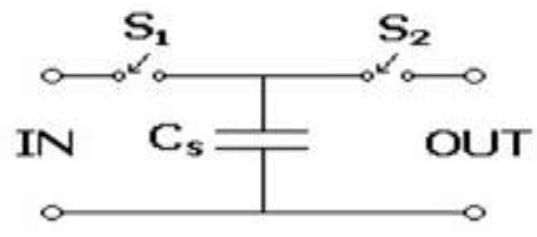

Figure 2. The parasitic sensitive integrator

This circuit is used to provide accurate voltage gain as well as performs the functions of an integrator shown in figure 2 .

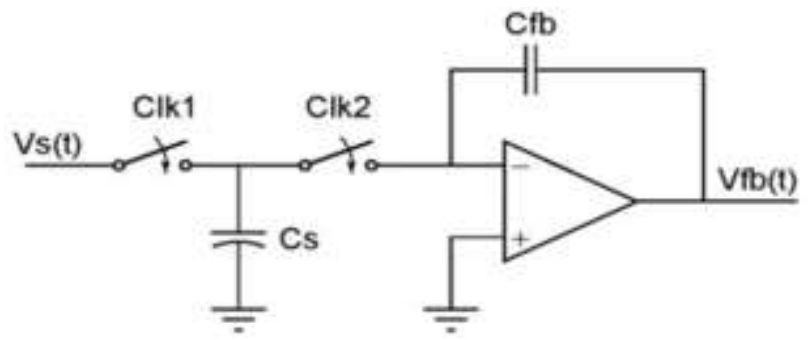

Figure 3. Discrete time system 


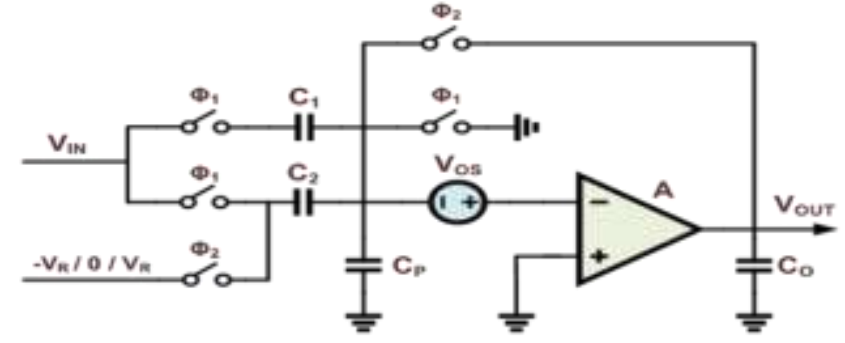

Figure 4. Micro fabrication-

A discrete time system processes as shown in figure 3 . It is a process based on micro machining. The process of fabrication matches that of CMOS fabrication. AntennasComponents like RF MEMS switches and reactors so as to take advantage of low insertion loss and high $\mathrm{Q}$ factor. The range of frequencies can go from 2.4 to $18 \mathrm{GHz}$. FiltersThese filters can be used in case the antennas failed. The size of the filter decreases when it is a Tunable RF band pass filter. Phase shifters- The applications of these devises include controlling the elative phase of each element in a phase array antennae. TTD (True Time Delay) phase shifter allows UWB radar waveforms with high range resolution [9-10]. 2 distinct conditions are chosen when the converter operates in the motoring mode, if the power gradient on the load side is between -3500 watts to +3500 watts, battery modules supply energy to the load otherwise UC modules supply power to the load [11-12].

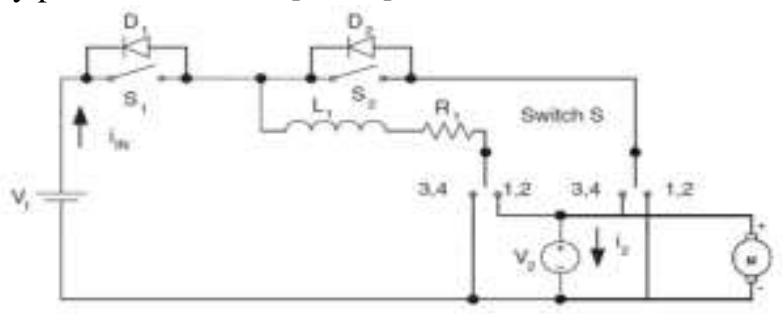

Figure.5. Four quadrants operations of in the LUO converter

\section{SIMULATION RESULTS AND DISCUSSIONS}

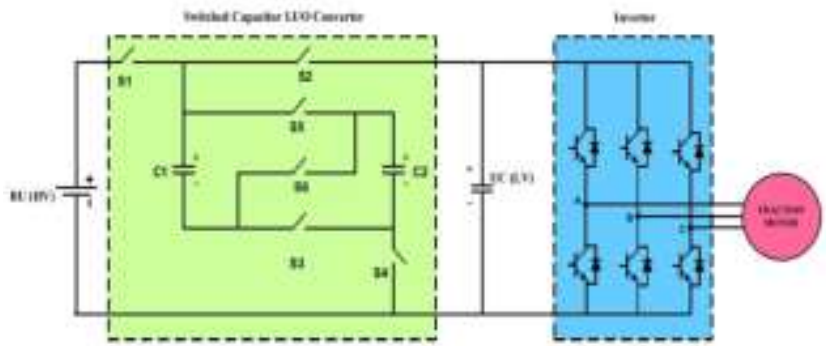

Figure 6. Simulation diagram of proposed method

The distributed load line principle or switched line principle is used in designing TDD phase shifters. Electrical load- Any device that is connected to a power line and derives power is called a load. Load affects the performance of the power line.

DC motor- A motor is any device that converts electrical power to mechanical power and is divided into many types. First being the brushed motor. This motor generates torque as it is directly connected to the power line. It works on the principle of Lorentz force. The advantages of this motor are reliability and low initial cost. Disadvantages include high maintenance and low life span. The other type is the synchronous motor. The commutation is external in this motor when compared to that of the brushed motor which is internal. The last type is the brushless motor which uses a permanent magnet in the rotor. Advantages include long life span and low maintenance whereas the disadvantages include high initial cost and complicated controls.

Controller implementation - As the controller directs the rotations of the rotor, it needs some sort of orientation determiner of the rotor. The DC output of the controller appears to be trapezoidal. The controllers are equipped with three bi directional drivers to drive the high DC power. The BLDC motors dominate many applications of today ranging from CD/DVD players to cooling fans. These can be constructed in several different physical configurations. In all BLDC motors all coils are stationary.

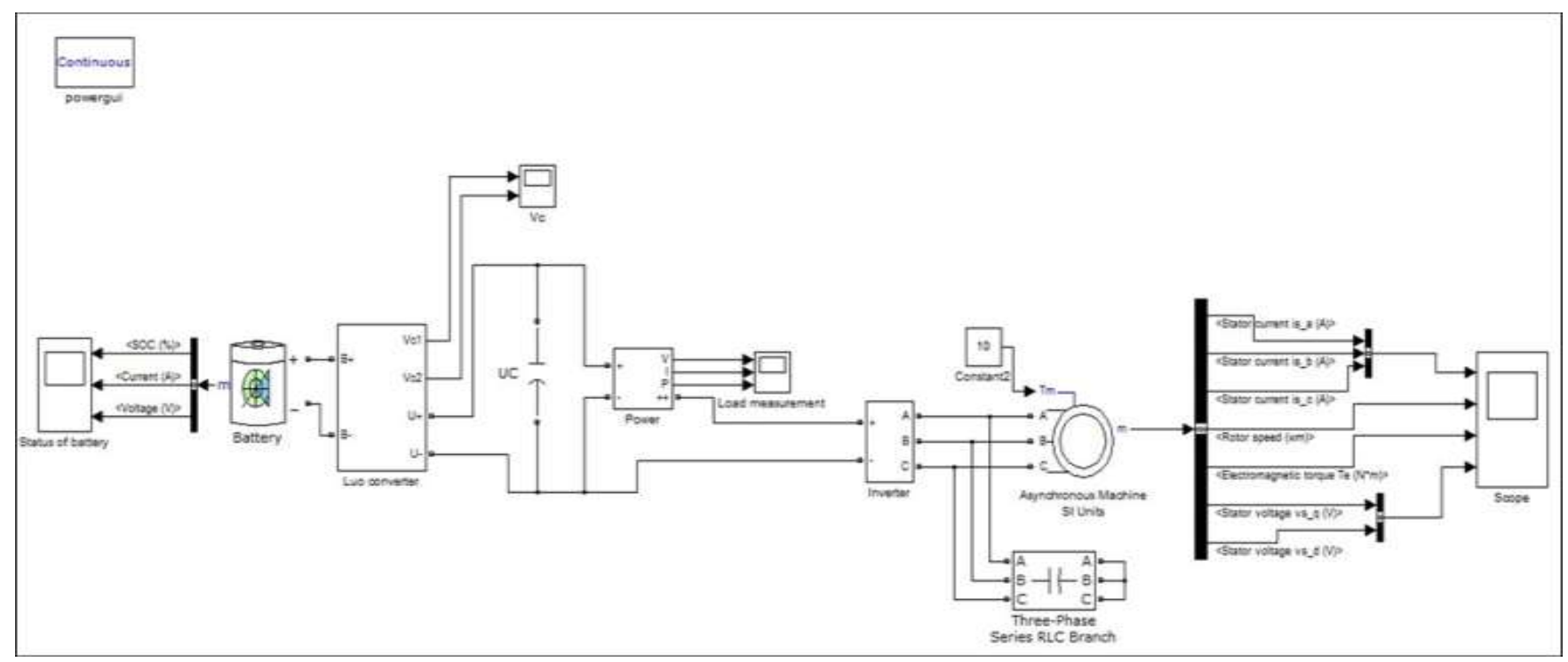

Figure 7. Simulation of switched capacitance 

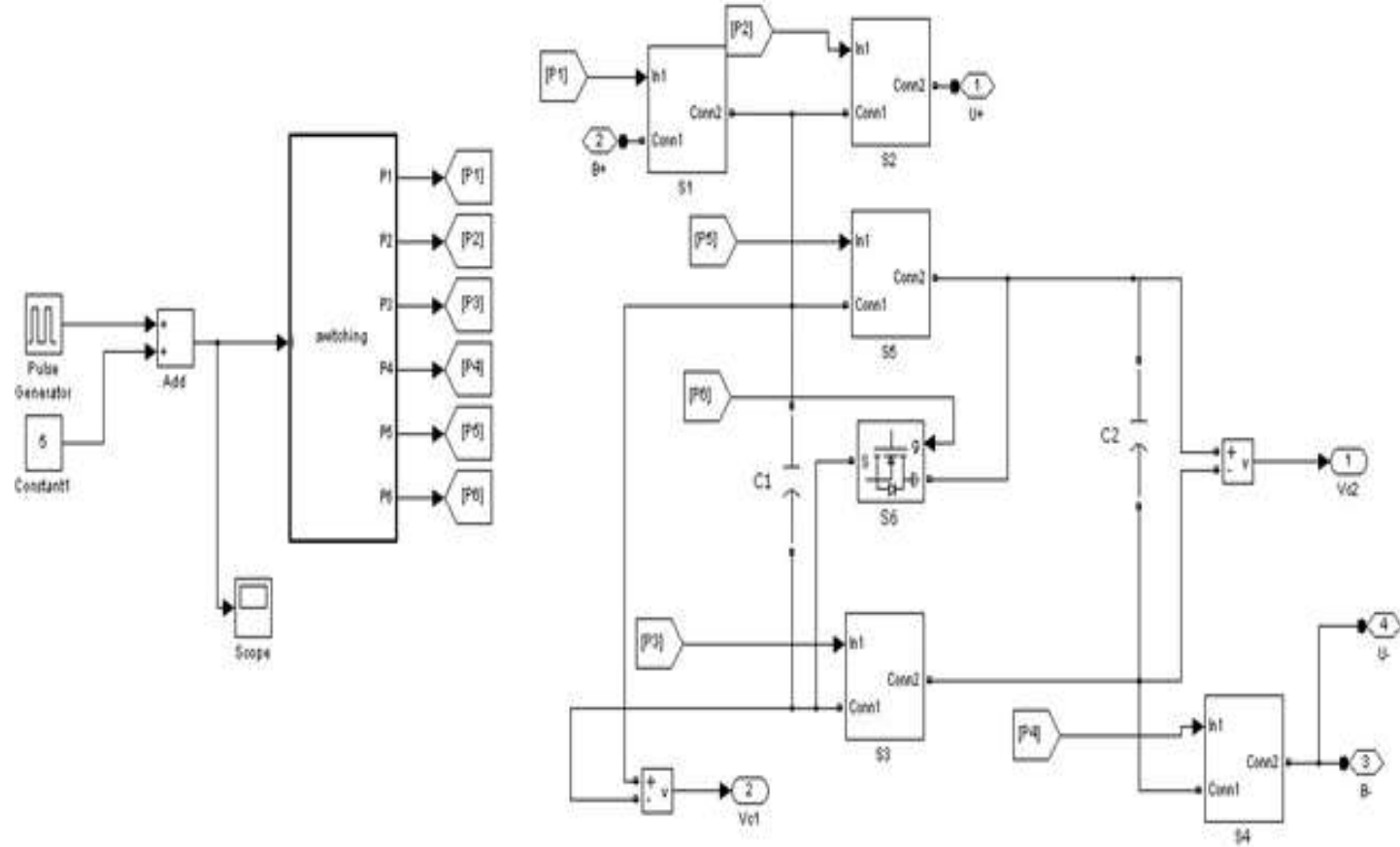

Figure 8. Diagram for LUO converter

f0A $=529 \mathrm{~Hz}, \mathrm{QA}=0.785 \mathrm{f0B}=993 \mathrm{~Hz}, \mathrm{QB}=3.559$ for unity

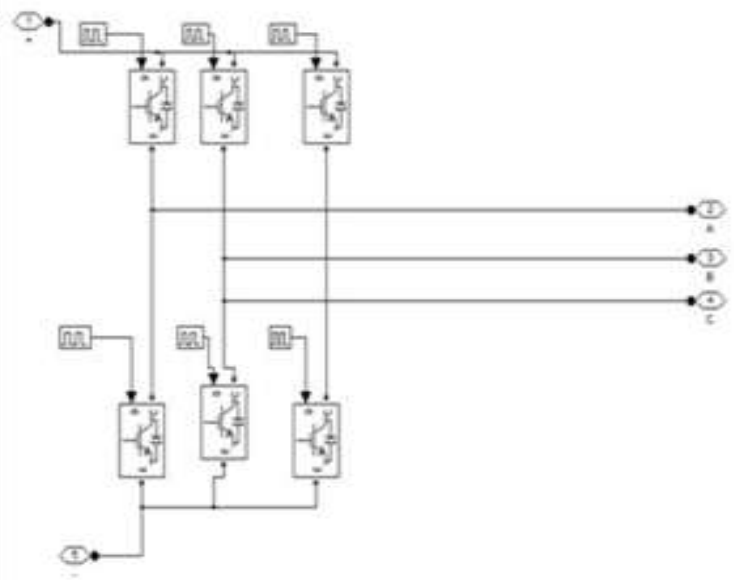
gain at $\mathrm{DC}, \mathrm{H} 0 \mathrm{~A}=1, \mathrm{H} 0 \mathrm{~B}=1$

A stage with lower $\mathrm{Q}$ is placed ahead of a higher $\mathrm{Q}$ as this will provide attenuation at the center frequency. The simulation of switched capacitance, LUO converter, inverter shown in figure 7, 8 and 9 respectively.

Figure 9. Circuit diagram for inverter

This paper proposes a new controller design for a 2-quadrant SC LUO converter for high voltage energy storage and energy management applications.

To design this device, the following parameters were specified:- 

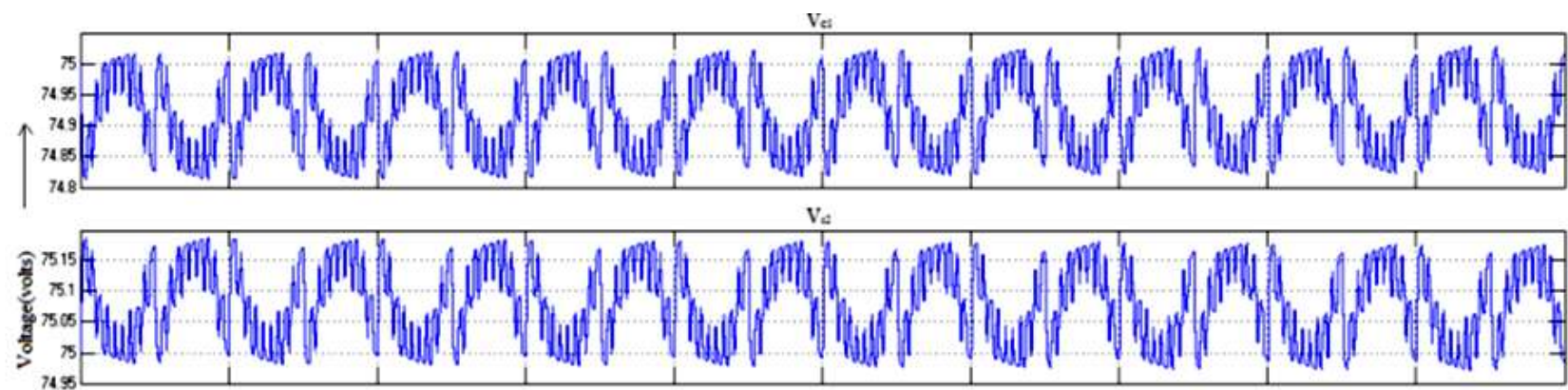

$V_{a}+V_{s}$

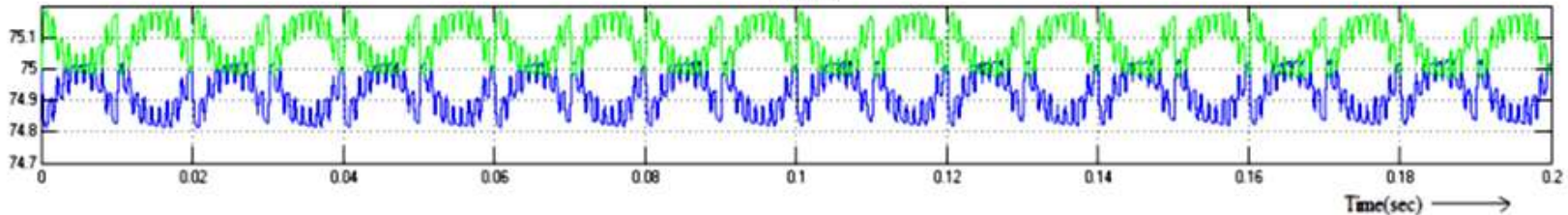

Figure 10. Capacitor voltages

The output capacitor voltage are illustrated in figure 10 . The total harmonics distortion of this proposed method is 16 are demonstrated in figure 11 . The output voltage of inverter after filter with amplitude $270 \mathrm{~V}$ shown in figure 12.
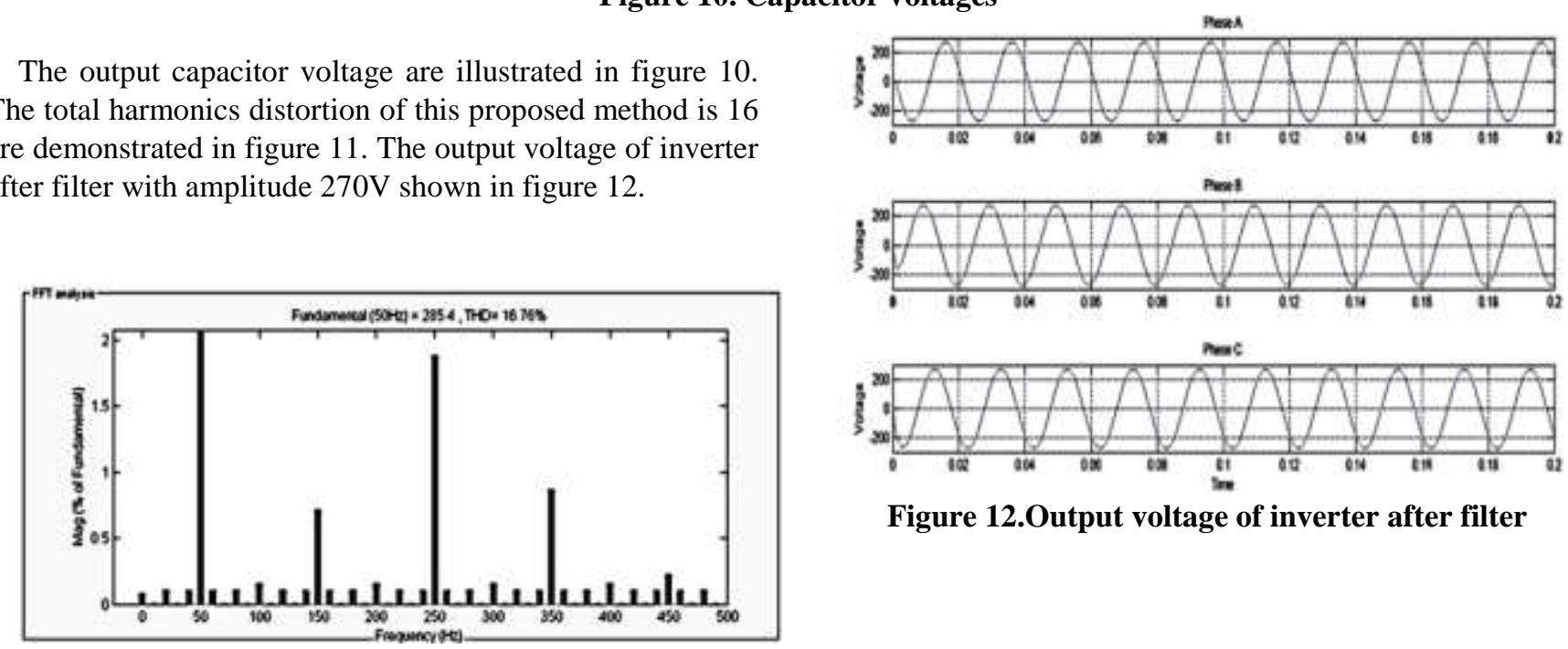

Figure 12.Output voltage of inverter after filter

Figure 11. Total harmonics distortion
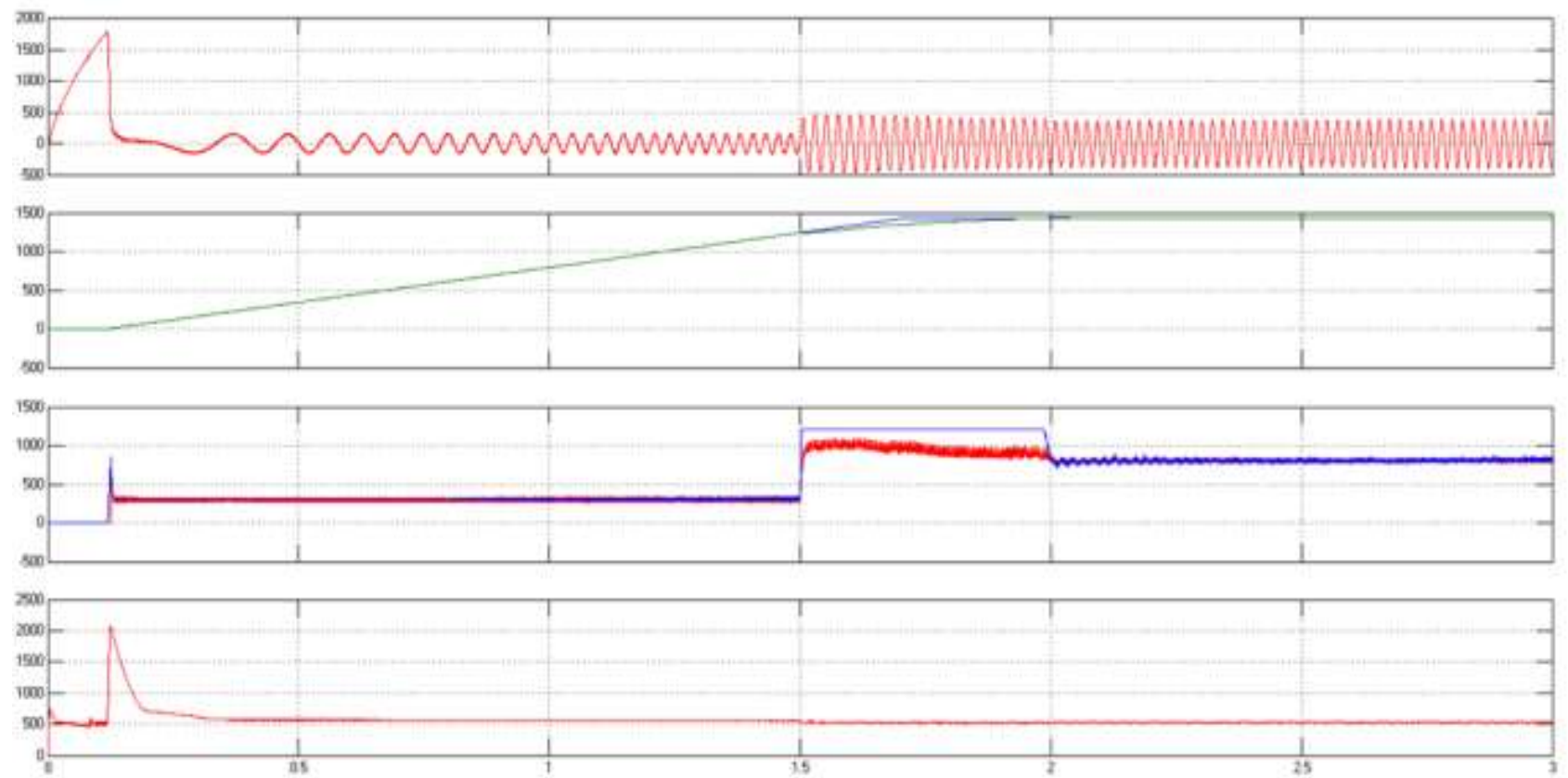

Figure 13. Performance of motor 
The DC bus voltage, torque, speed and stator current of motor are illustrated in figure 13.at the starting the amplitude of DC bus voltage if high then reduced to $500 \mathrm{~V}$. The reverence speed and actual speed of the motor are matched from 0 seconds to 1.5 seconds from 1.5 seconds to 1.8 seconds there is a slight deviation after that speed is again matched with reference speed.

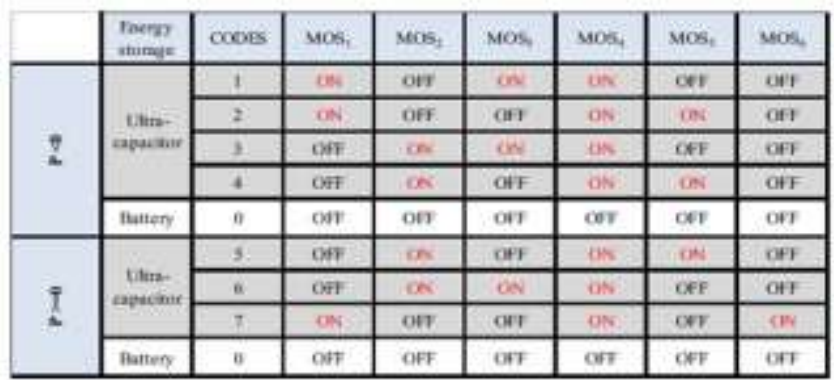

Table 1.Switched codes

\section{CONCLUSION}

This proposed design was completed successfully with the advantages like Good regulation capability, Ease of speed control and balanced capacitor voltage. A Proportional-Integral control has been designed for the positive output of the Elementary Super Lift LUO Converter which uses the voltage lift capability to donate a less ripple, very high power density, higher efficiency, voltage gain and a less complicated structure.

\section{REFERENCES}

1. Y.He, F.L.Luo;"Analysis of Luo converters with voltage-lift circuit", IEE-Proceeding on Electric Power Application, Vol.152, pp.1239-1252.Sep. 2005.

2. Luo F. L., Ye H. and Rashid M. H, " Four-Quadrant operating Luo-Converters" Proceedings of the IEEE International Conference PESC'2000, Galway, Ireland, 18-23 June 2000, pp. 1047-1052.

3. Luo.F.L,HongYe, Rashid.M.H, 'Switched Capacitor Four Quadrant DC/DC Luo Converter', Industry Applications Conference, Vol.3, 1999.

4. S.R. Sanders, J.M. Noworolsky, X.Z. Liu and G.C. Varghese, "Generalized averaging method for power conversion circuits," IEEE Trans. Power Electronics, vol. 6, pp. 251-259, Apr. 1991.

5. J. Sun and H. Grotstollen, "Symbolic analysis methods for averaged modeling of switching power converters," IEEE Trans. Power Electronics, vol. 12, pp. 537-546, May 1997.

6. Kugi and K. Schlacher, "Nonlinear \&-controller design for a DC-to-DC power converter," IEEE Trans. Contr. System Technology, vol. 7, pp. 230-237, Mar. 1999.

7. G. Escobar, R. Ortega, H. Sira-Ramirez, J.P. Vilain and I. Zein, "An experimental comparison of several nonlinear controllers for power converters," IEEE Control Systems, vol. 19, no. 1, pp. 66-82, Feb. 1999.

8. Harris.W.S, Ngo.K.D.T,' Power Switched Capacitor DC/DC Converter; Analysis and Design, Aerospace and Electronic System, IEE Transaction on Vol.33,Issue 2,1997

9. F.L. Luo, "Luo converters, voltage lift technique," in proc. IEEE Power Electron. Spec. Conf., Fukuoka, Japan, may1998, pp.1783-1789.

10. Luo F. L. -Double Output Luo-Converters, Advanced Voltage Lift Technique- IEEE Proceedings on Electric Power Applications, Vol. 147, No. 6, November 2000, pp.

11. T. S. Saravanan, R. Seyezhai and V. Venkatesh "modeling and control of split capacitor type elementary additional series positive output super lift converter", ARPN Journal of Engineering and Applied Sciences, vol. 7, no. 5, may 2012

12. Axelrod B., Berkovich Y., Ioinovici A -Switched-Capacitor/Switched-Inductor Structures for Getting Transformer less Hybrid DC-DC PWM Converters\| IEEE Trans. Circuits and Systems, 55, (2), 2008, pp. 687-696. 